\title{
Front Matter: Volume 7396
}

, "Front Matter: Volume 7396," Proc. SPIE 7396, Physical Chemistry of Interfaces and Nanomaterials VIII, 739601 (2 September 2009); doi: $10.1117 / 12.844845$

SPIE Event: SPIE NanoScience + Engineering, 2009, San Diego, California, United SPIE. States 


\section{PROCEEDINGS OF SPIE}

\section{Physical Chemistry of Interfaces and Nanomaterials VIII}

Oliver L. A. Monti

Oleg V. Prezhdo

Editors

2-4 August 2009

San Diego, California, United States

Sponsored and Published by

SPIE 
The papers included in this volume were part of the technical conference cited on the cover and title page. Papers were selected and subject to review by the editors and conference program committee. Some conference presentations may not be available for publication. The papers published in these proceedings reflect the work and thoughts of the authors and are published herein as submitted. The publisher is not responsible for the validity of the information or for any outcomes resulting from reliance thereon.

Please use the following format to cite material from this book:

Author(s), "Title of Paper," in Physical Chemistry of Interfaces and Nanomaterials VIII, edited by Oliver L. A. Monti, Oleg V. Prezhdo, Proceedings of SPIE Vol. 7396 (SPIE, Bellingham, WA, 2009) Article CID Number.

ISSN 0277-786X

ISBN 9780819476869

Published by

SPIE

P.O. Box 10, Bellingham, Washington 98227-0010 USA

Telephone +1 3606763290 (Pacific Time) · Fax +1 3606471445

SPIE.org

Copyright (C) 2009, Society of Photo-Optical Instrumentation Engineers

Copying of material in this book for internal or personal use, or for the internal or personal use of specific clients, beyond the fair use provisions granted by the U.S. Copyright Law is authorized by SPIE subject to payment of copying fees. The Transactional Reporting Service base fee for this volume is $\$ 18.00$ per article (or portion thereof), which should be paid directly to the Copyright Clearance Center (CCC), 222 Rosewood Drive, Danvers, MA 01923. Payment may also be made electronically through CCC Online at copyright.com. Other copying for republication, resale, advertising or promotion, or any form of systematic or multiple reproduction of any material in this book is prohibited except with permission in writing from the publisher. The CCC fee code is 0277-786X/09/\$18.00.

Printed in the United States of America.

Publication of record for individual papers is online in the SPIE Digital Library.

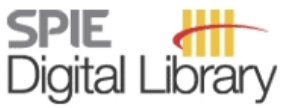

SPIEDigitalLibrary.org

Paper Numbering: Proceedings of SPIE follow an e-First publication model, with papers published first online and then in print and on CD-ROM. Papers are published as they are submitted and meet publication criteria. A unique, consistent, permanent citation identifier (CID) number is assigned to each article at the time of the first publication. Utilization of CIDs allows articles to be fully citable as soon they are published online, and connects the same identifier to all online, print, and electronic versions of the publication. SPIE uses a six-digit CID article numbering system in which:

- The first four digits correspond to the SPIE volume number.

- The last two digits indicate publication order within the volume using a Base 36 numbering system employing both numerals and letters. These two-number sets start with 00, 01, 02, 03, 04, $05,06,07,08,09,0 A, 0 B \ldots 0 Z$, followed by 10-1Z, 20-2Z, etc.

The CID number appears on each page of the manuscript. The complete citation is used on the first page, and an abbreviated version on subsequent pages. Numbers in the index correspond to the last two digits of the six-digit CID number. 


\section{Contents}

$\checkmark$ Conference Committee

vii Introduction

ix Sub-nanometer resolution for the inspection of reflective surfaces using white light (Plenary Paper) [7405-37]

W. Jüptner, T. Bothe, Bremer Institut für angewandte Strahltechnik (Germany)

\section{INTERFACES IN CATALYSIS}

739604 The influence of surface hydration on the interfacial electron transfer dynamics from Rhodamine B into $\mathrm{SnO}_{2}$ (Invited Paper) [7396-23]

R. C. Snoeberger III, Yale Univ. (United States); T. Lian, Emory Univ. (United States);

V. S. Batista, Yale Univ. (United States)

\section{STRUCTURE AND DYNAMICS IN NANOPARTICLES}

739607 Photoexcitation of the triplet exciton in single wall carbon nanotubes (Invited Paper) [7396-03]

B. W. Alphenaar, A. D. Mohite, Univ. of Lovisville (United States); J. S. Moodera, T. S. Santos, Massachusetts Institute of Technology (United States)

\section{INTERFACES IN ORGANIC ELECTRONIC DEVICES}

7396 OB Hybrid organic-inorganic POSS dendritic materials: photoluminescence chromophore control via confinement and steric hindrance [7396-07]

P. André, G. Cheng, A. Ruseckas, D. J. Cole-Hamilton, I. D. W. Samuel, Univ. of St. Andrews (United Kingdom) and Organic Semiconductor Ctr. (United Kingdom)

7396 OC Energy-level alignment of aryl thiols chemisorbed on metal surfaces: implications for charge transport (Invited Paper) [7396-16]

C. D. Zangmeister, S. W. Robey, R. D. van Zee, National Institute of Standards and Technology (United States); N. E. Gruhn, The Univ. of Arizona (United States); Y. Yao, J. M. Tour, Rice Univ. (United States)

\section{SINGLE NANOPARTICLES: SYNTHESIS AND SPECTROSCOPY}

7396 OF Controlling the optical properties of single molecules by optical confinement in a tunable microcavity [7396-11]

A. Chizhik, R. Gutbrod, A. Chizhik, S. Baer, A. Meixner, Eberhard Karls Univ. Tübingen (Germany) 
7396 OG Investigation of ultrafast carrier dynamics in $\mathrm{ZnO}$ rods using two-photon emission and second harmonic generation microscopy (Invited Paper) [7396-12]

R. L. House, B. P. Mehl, C. Zhang, J. R. Kirschbrown, S. C. Barnes, J. M. Papanikolas, The Univ. of North Carolina at Chapel Hill (United States)

\section{ELECTRONIC STRUCTURE AND DYNAMICS AT INTERFACES}

739600 Electronic confinement effects and optical properties of multilayer slabs of silicon: numerical model studies (Invited Paper) [7396-19]

C. J. Obara, Univ. of Florida (United States) and National Institutes of Health (United States);

D. S. Kilin, D. A. Micha, Univ. of Florida (United States)

7396 OP Direction-dependent intermolecular interactions: catechol on $\mathrm{TiO}_{2}(110)-1 \times 1$ (Invited Paper) [7396-20]

S.-C. Li, U. Diebold, Tulane Univ. (United States)

\section{CHARGE TRANSFER PROCESSES AND EXCITATIONS: JOINT SESSION WITH CONFERENCE} 7416

$73960 Q \quad$ Two-dimensional IR-visible sum frequency generation spectroscopy: a unique probe of surface electronic states at buried interfaces (Invited Paper) [7396-25]

Q. Li, K. C. Chou, The Univ. of British Columbia (Canada)

7396 OR Non-thermal free carrier formation in organic photovoltaic polymer blends [7396-26]

R. D. Pensack, L. W. Barbour, M. Hegadorn, J. B. Asbury, The Pennsylvania State Univ. (United States)

\section{POSTER SESSION}

7396 ОT Electron structure of $\mathrm{AgCl}$ nanocrystal with silver ion adsorbed on atomic-rough surface and quantum transitions [7396-02]

Y. K. Timoshenko, Voronezh State Univ. (Russian Federation); V. A. Shunina, Voronezh State Technical Univ. (Russian Federation) and Voronezh State Univ. (Russian Federation)

7396 OU Effect of solvent on morphological properties of TiO $x$ thin film [7396-28]

M.-Y. Liu, C.-H. Chang, C.-H. Chang, J.-S. Huang, C.-S. Chao, Y.-H. Lin, W.-H. Lin, C.-F. Lin, National Taiwan Univ. (Taiwan)

Author Index 


\title{
Conference Committee
}

\author{
Symposium Chairs \\ David L. Andrews, University of East Anglia Norwich (United Kingdom) \\ James G. Grote, Air Force Research Laboratory (United States) \\ Conference Chair
}

Oliver L. A. Monti, The University of Arizona (United States)

Cochairs

Oleg V. Prezhdo, University of Washington (United States)

Sergei Tretiak, Los Alamos National Laboratory (United States)

Program Committee

John B. Asbury, The Pennsylvania State University (United States)

Session Chairs

1 Interfaces in Catalysis

Oleg V. Prezhdo, University of Washington (United States)

2 Structure and Dynamics in Nanoparticles

Oliver L. A. Monti, The University of Arizona (United States)

3 Interfaces in Organic Electronic Devices

Oliver L. A. Monti, The University of Arizona (United States)

$4 \quad$ Single Nanoparticles: Synthesis and Spectroscopy

Andrei Piryatinski, Los Alamos National Laboratory (United States)

$5 \quad$ Electronic Structure at Interfaces

John B. Asbury, The Pennsylvania State University (United States)

$6 \quad$ Electronic Structure and Dynamics at Interfaces

John B. Asbury, The Pennsylvania State University (United States)

7 Charge Transfer Processes and Excitations: Joint Session with Conference 7416

David G. Lidzey, The University of Sheffield (United Kingdom) 
Downloaded From: https://www.spiedigitallibrary.org/conference-proceedings-of-spie on 26 Apr 2023

Terms of Use: https://www.spiedigitallibrary.org/terms-of-use 


\section{Introduction}

The rapidly growing capabilities of engineering complex organic, inorganic, and hybrid materials into functional electronic, catalytic or sensing devices has generated the clear need for a fundamental understanding of the role of interfaces. This is particularly true in the case of nanostructured assemblies whose very nature is intrinsically dominated by surfaces. Even the most perfect structures currently available may be dominated by defects and structural relaxations, with a disproportionate impact on nonequilibrium interfacial processes such as charge and energy transfer. Interfaces may be disordered, and the role of disorder is far from understood. At the nanoscale, confinement effects may be critically determined by the presence of interfacial states, generating intergap states with a profound influence on the dynamics and function of the structures. The choice of a theoretical framework is governed by understanding the delicate balance between dispersive band-like states familiar from solid state physics and the more localized picture of molecular wavefunctions. A quantitative theoretical understanding is only now starting to emerge, since most such structures occupy a size regime that is at the absolute limit of accurate computational methodology. At the same time, experimentally observing selectively the interface remains a difficult task, in particular once measurements are performed outside extreme conditions and in realistic environments. These restrictions pose severe challenges to understanding interfaces and nanomaterials that can only be tackled by a cutting-edge combination of both theory and experiment.

The proceedings of this conference, the eighth in this series, are testimony to the rapid advances being made in this field. The presentations cover length-scales from single molecules to models of functioning devices, and time-scales from fs to many hours. As is evident from the abstracts and proceedings of this conference, in developing novel experimental techniques and steadily improving the performance of more established ones, in conjunction with sophisticated advances in computational methods and synthetic capabilities, a deeper understanding of the physics at interfaces and in nanostructures is starting to emerge slowly. Out of all this work arises an outline of a refined theoretical framework of how molecular and bulk descriptions blend, how interfaces must be treated at the conceptual level and how they may perhaps even be manipulated in a controlled fashion. This volume is a snap-shot of the state-of-theart in 2009, much remains to be achieved building on the advances presented here.

Oliver L. A. Monti 
Downloaded From: https://www.spiedigitallibrary.org/conference-proceedings-of-spie on 26 Apr 2023

Terms of Use: https://www.spiedigitallibrary.org/terms-of-use 


\title{
Sub-Nanometer Resolution for the Inspection of Reflective Surfaces Using White Light
}

\author{
Werner Jüptner, Thorsten Bothe \\ c/o BIAS, Klagenfurter Str. 2, D-27721 Bremen, Germany
}

\begin{abstract}
The quality control of highly reflective surfaces requires a measurement method which is able to resolve the surface shape in the nanometer range. Different methods have been developed in the past, e.g. based on interferometry or by tactile coordinate measurement machines. However, most of them do not match the industrial need for a fast method which is insensitive to environmental disturbance.

The newly developed method using the reflection of fringe pattern by the surface under test, and therefore called "Fringe Reflection Technique (FRT)", overcomes the difficulties of known measurement methods. In this method a pattern of straight fringes is generated by a monitor. The mirrored pattern is observed by a camera via the object surface under test. Any deviation of the surface against the ideal, i.e. the mathematically accurate surface will yield a distortion of the pattern. This distortion is analyzed by an image processing system, called the Fringe Processor. The surface topology is delivered by local surface gradients which can be integrated to object shape or differentiated to local curvature. The resolution of the system can be adapted to the measurement requirements in a wide range from micrometer down to subnanometer. Anyhow, the system is stable against environmental disturbances. It works without vibration isolation in rooms without any climate control. It is possible to measure freeform surfaces with no constraints on object geometry.
\end{abstract}

The measurement of a silicon mirror surface produced by diamond turning in a high precision tool machine serves as one example. The surface shape could be determined with a resolution below one nanometer. The measurements match the results of an interferometer and are better in certain areas.

Keywords: Shape, reflectometry, white light, nanometer resolution, topometry, freeform

\section{INTRODUCTION}

Shape measurements with a resolution down into the nanometer range are getting an increasingly importance [1], not only for the micro- and nano-system production but for standard products like coatings on cars or mirrors. Different metrology technologies have been developed in the past like phase sensitive microscopy, confocal microscopy, atomic force microscopy, or scanning near field optical microscopy [2]. The majority of these high resolution technologies are based on a point wise acquisition of the data and a scanning system for the determination of the whole surface topology. Furthermore, the methods are mostly sensitive to environmental disturbance.

The Fringe Reflection Technology (FRT) [3] is a whole field measurement technique using the imaging of fringes via the object surface: A fringe system displayed by a monitor is observed after the reflection by the object surface. Any tilt of the object surface changes the angle of reflection. This yields in a displacement of the fringe system to be measured by means of an image processing system. The displacement is strongly related to the angle of the surface against the bisector of the angle between camera normal and monitor normal. If this is the angle of a local part of the surface then it can be indicated as the surface gradient at this point, i.e. the FRT provides primarily the gradient field of the surface shape. By integration, the shape can be evaluated down to nanometers [4]. The FRT enables the characterization of reflective - not even specular - surfaces which cannot be measured by means of standard optical or tactile methods.

The basics of the FRT are described in the first part of this paper. The method can be used in a number of adapted setups. But in principle a monitor with software generated sinusoidal fringes and a CCD camera with an image processing system is needed. The nest point is the description of the data generation and the resolution that can be achieved depending on the parameters of the system.

Three examples of application will be described in order to demonstrate the wide variety of possible measurements with high resolution.

Instrumentation, Metrology, and Standards for Nanomanufacturing III, edited by Michael T. Postek, John A. Allgair, Proc. of SPIE Vol. 7405, 740502 - (c) 2009 SPIE · CCC code: 0277-786X/09/\$18 · doi: 10.1117/12.838373 


\section{FUNDAMENTALS OF THE FRINGE REFLECTION TECHNIQUE}

\subsection{Principle of the FRT and the Set-up}

The basic set-up of a fringe reflection set-up comprises three hardware components, Fig.1:

- a monitor to display parallel sinusoidal fringes,

- a CCD camera as a part of an image processing system, and

- the object under investigation.

The camera on top of the monitor, Fig.1a, observes the fringe system via the object under investigation via the test object, in this case a car front window, Fig. $1 \mathrm{~b}$ left. The object is reflective by condition of the method, i.e. the fringe system is visible even when the surface is only partly specular. The camera is focused onto the surface of the object, Fig.1c. This results in a blurred image of the fringe system. However, a sinusoidal fringe remains sinusoidal under blurred conditions, too. A flat mirror would cause an undistorted image of the fringe system. Any tilt of the surface or a part of it displaces the related fringe system. A curved object will deform the former straight parallel fringe system according to the local angle of the surface against the normal or in other terms according to the surface gradient. The reflected fringe system is measured using a phase shifting method [5] and evaluated by means of an image processing system [6].
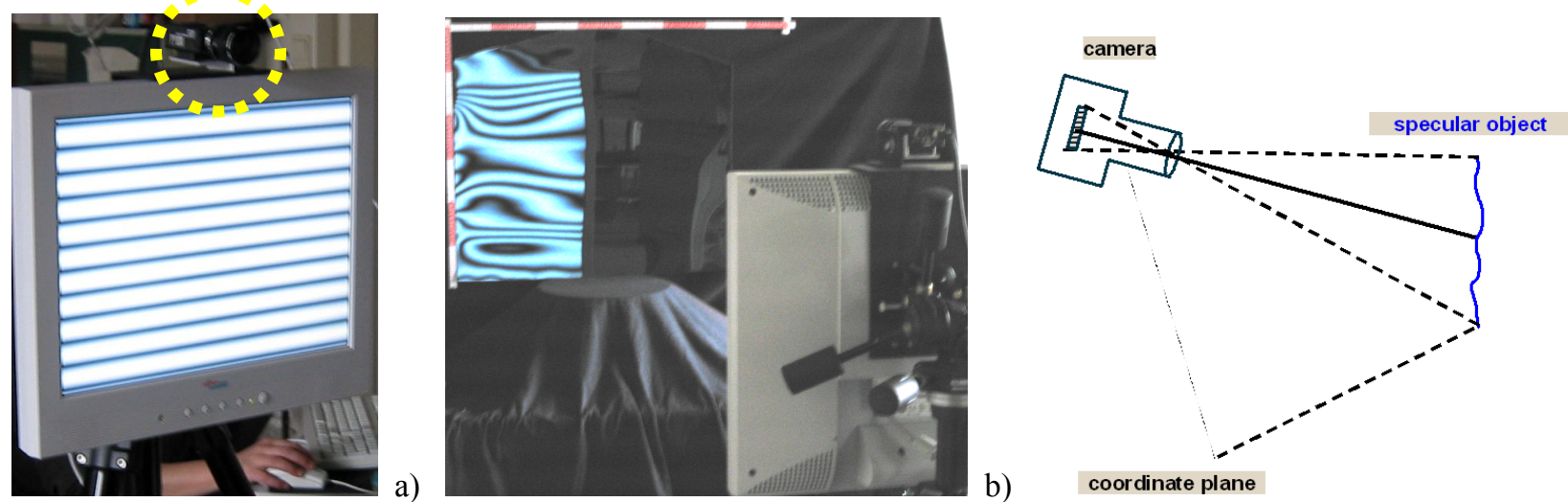

c)

Fig. 1. System components: a) monitor displaying the fringe system and a CCD camera fixed on top of the monitor (dash line circle), b) car window (test object) at the left and monitor from back side at the right, c) schematic sketch

\subsection{Geometrical Model and Evaluation}

The evaluation will be derived on a geometrical model neglecting the scattered part of the light coming from the object, Fig.2. A surface angle of $\Delta \alpha / 2$ against the normal yields a deflection of the reflected image by an angle $\alpha$ according to the laws of optics and by this a displacement of $\Delta s$ of the imaged fringe system on the target in the distance $l$ from the
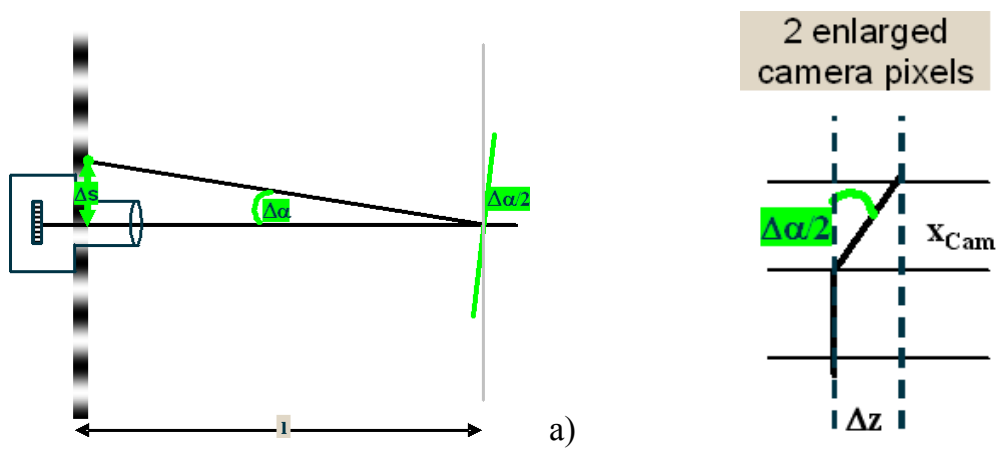

a)

b)

Fig. 2. Evaluation model: a) geometrical relations of fringe displacement, b) gradient and displacement angle

object. The deflection is caused by a local gradient of the surface $\Delta \alpha / 2$ - the same as above - which is given by the

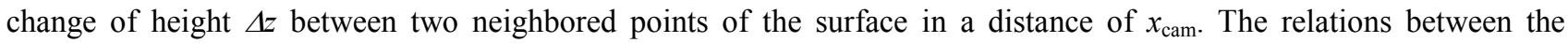
geometrical quantities are given by: 


$$
\begin{gathered}
\tan \alpha=\frac{\Delta s}{l} \\
\tan \frac{\alpha}{2}=\frac{\Delta z}{x_{c a m}} \\
\Delta z \approx \frac{\Delta s}{2 l} x_{c a m}
\end{gathered}
$$

and:

In this equation $x_{\text {cam }}$, - the size of an "object point" on the target - is given by the linear dimension of the object divided by the pixel number. The distance 1 is a measurable parameter of the set-up. The displacement of the fringe system - or the regarded part of it - has to be determined by image processing. Since the displacement shifts the fringe system by parts of the period the local phase of the fringes must be measured. For this, phase shifting technique is the state of the art [5]. In order to evaluate the minimum phase shift to be resolved in a given set-up one has to take into account the imaging system, Fig.3. The distance 1 from the camera to the object is the same as the distance from the monitor to the object assuming that the camera is fixed on the monitor or close to it. It can be derived by the geometrical relations:

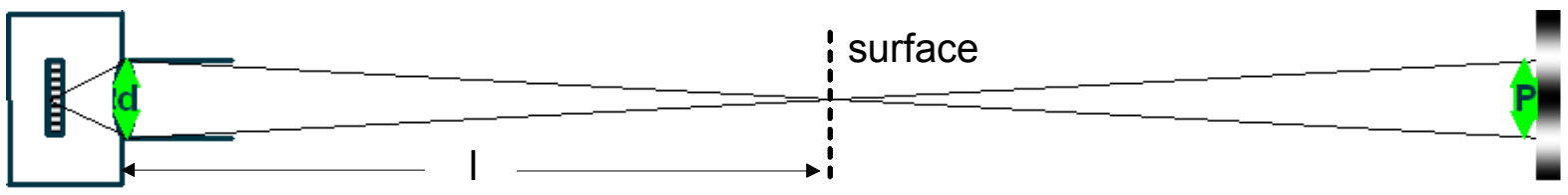

Fig. 3. Geometrical model of the imaging: the circle of confusion has identical aperture size in double focus distance

$$
\frac{\Delta s}{P}=\frac{\Delta \varphi}{2 \pi} \quad \text { or } \quad \Delta s=P \frac{\Delta \varphi}{2 \pi}
$$

with $\quad \Delta s:$ smallest displacement to be measured

$\Delta \varphi$ : smallest phase change to be measured
$P: \quad$ smallest possible period of the fringe system

$2 \pi$ : full fringe angle

The geometry of the set-up yields the equality $d=P$, Fig.3. With the focal length $f$ and the f-number $k$ the size of $d$ is

$$
d=\frac{f}{k}
$$

Equ.(5) together with Equ.(4) leads to

$$
\Delta s=\frac{f}{k} \frac{\Delta \varphi}{2 \pi}
$$

Combining Equ.(6) with Equ.(3) results in

$$
\Delta z=x_{\text {cam }} \frac{f}{l} \frac{1}{2 k} \frac{\Delta \varphi}{2 \pi}
$$

$x_{\text {cam }}$ is the distance between two neighbored object points; $f / l$ is the reduction of the object size by the imaging. The product of $x_{\text {cam }}$ and the reduction is the distance of two neighbored points on the target which is the size of a camera pixel. $\Delta \varphi / 2 \pi$ is the smallest resolvable phase change. Taking these relations into account results in equation for the height resolution $\Delta z$ as a function of the camera pixel size pixel, the aperture $k$ and the phase resolution $\Delta \varphi / 2 \pi$ :

$$
\Delta z=\operatorname{pixel} \frac{1}{2 k} \frac{\Delta \varphi}{2 \pi}
$$

There are three parameters in this equation that influence the resolution: 
- The camera pixel size pixel is given by the available targets and is approximately $10 \mu \mathrm{m}$ for a common camera.

- The aperture $k$ of the imaging objective which is close to 10. This value cannot be extended very much since a smaller aperture yields less light and by this more noise in the camera signal.

- The resolvable phase change which is normally expected to be 1/100 in phase shifting. However, this value can be improved up to about $1 / 1000$.

Inserting the following values: $\Delta z=10 \mu \mathrm{m}, k=16, \Delta \varphi=2 \pi / 1000$ Equ.(8) results in the height resolution of $\Delta z=0.63 \mathrm{~nm}$

\subsection{Hierarchical Phase Shifting}

Phase shifting is the state-of-the-art method to measure the phase of a fringe with high resolution. The method applies sequential fringe systems with different periods or spatial frequencies. The largest period is adapted to the requirement of unambiguity; the smallest period is given to the possible resolution of the imaging system. In common the period from one fringe system is divided by a factor of 2 by simplicity. However, this is not the optimum as shown by Osten [8]: The next smaller period must be chosen with regard to the noise. Taking this into account the spatial frequency may be increased by a factor $a$ between two sequential fringe systems, Fig.4. The evaluation of the phase by fringe systems of
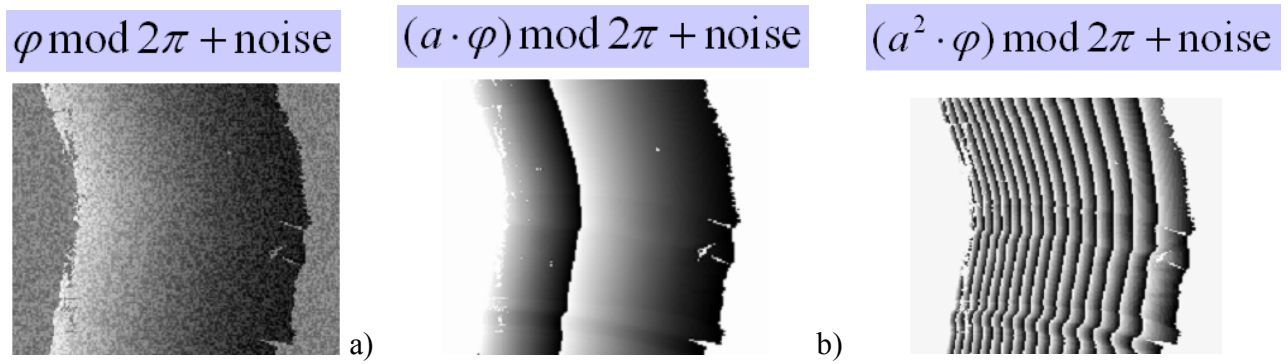

c)

Fig. 4. Sequential fringes system: a) fundamental spatial frequency, b) a times larger spatial frequency than a), c) a * a larger spatial than a)

according to Fig.4a and Fig.4b results in

$$
\varphi \bmod 2 \pi+\text { noise } \Rightarrow \varphi \bmod 2 \pi+\frac{\text { noise }}{a}
$$

Combining this result with the fringe system according to Fig.4c results in

$$
\varphi \bmod 2 \pi+\text { noise } \Rightarrow \varphi \bmod 2 \pi+\frac{\text { noise }}{a^{2}}
$$

This means that any additional fringe system in this sequence reduces the noise by a factor of $a$. Therefore highly resolved phase measurements can be achieved.

\subsection{Resolution of the FRT Applied to a Coated Mirror}

The surface of a coated mirror has been investigated in comparison with the FRT, with a commercial grating interferometer, and with a tactile coordinate measurement system, Fig.5a. The first step was to determine the shape of the whole
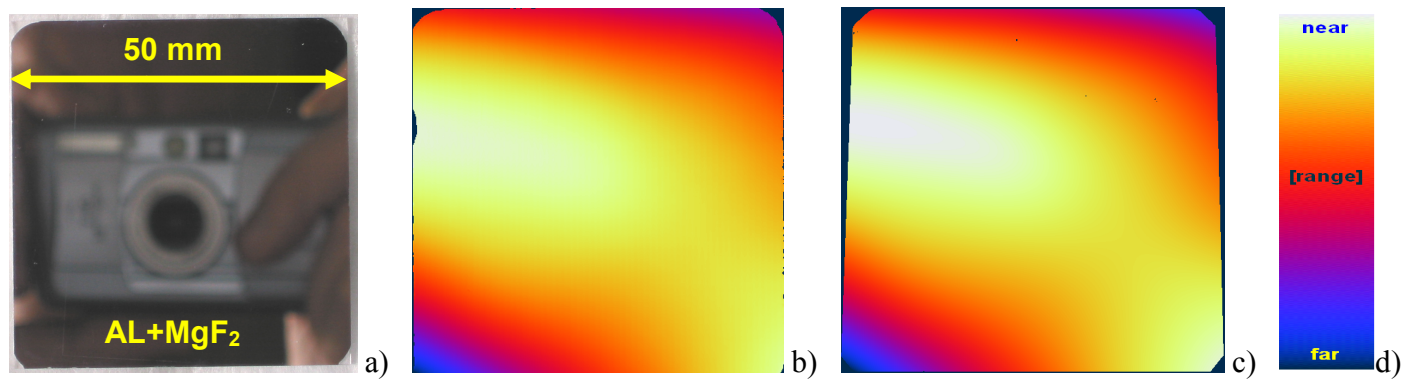

Fig. 5. Flat Al-mirror, $\mathrm{MgF}_{2}$ coated: a) Photo, shape measured a) by prating interferometer with range $21.4 \mu \mathrm{m}$, c) by FRT with range $18.8 \mu \mathrm{m}, \mathrm{d}$ ) color scale 
mirror by means of a commercial grating interferometer (by Zygo), Fig.5b) and by the fringe reflection technique, Fig.5c. The measurements showed a nearly cylindrical shape with a diagonal "hill" in the middle. The peak-to-valley value of the contour is about $20 \mu \mathrm{m}$. In a next step the first and second order components of the shape were removed by subtracting fitted polynomials. This yields the fine structure with peak-to-valley values of $15 \mathrm{~nm}$ for the FRT results, Fig. 6 b. The grating interferometer is not able to reach the same resolution by physical reasons of the method, Fig 6 a.
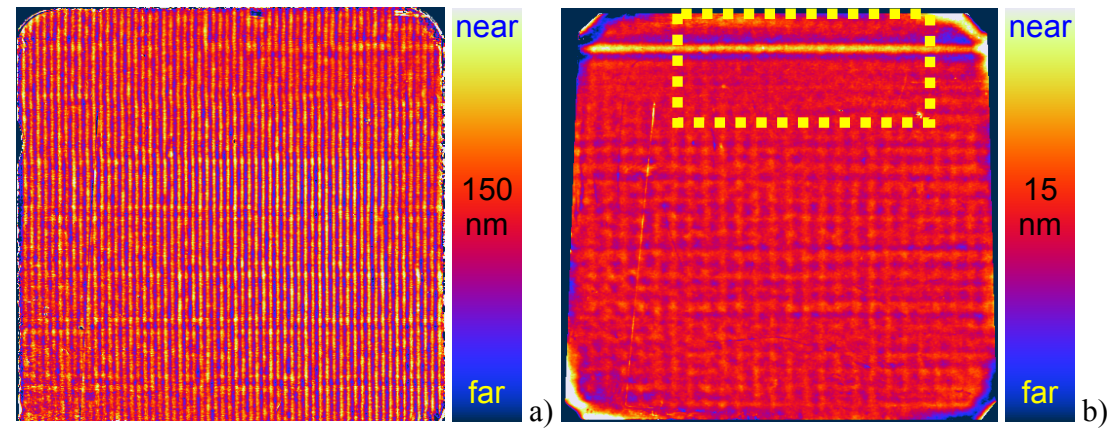

Fig. 6. Flat Al-mirror, $\mathrm{MgF}_{2}$ coated, third order shape components: a) grating interferometer, b) FRT

The results of the FRT should be compared to the results achieved with the tactile coordinate measurement machine Tencor P15 in the marked part of the mirror, Fig. 6b. The marked part of the mirror was investigated with the tactile method (Fig. 7a) and compared to the FRT result, Fig. 7b. The whole range of the surface structure is $11 \mathrm{~nm}$. This proofs that the resolution is below $1 \mathrm{~nm}$. It shall be pointed out that the FRT measurement was achieved with the original data for whole the mirror area. In conclusion: FRT is a robust shape measurement method with a resolution of better than $1 \mathrm{~nm}$ and a dynamic range of more than 1:10,000.
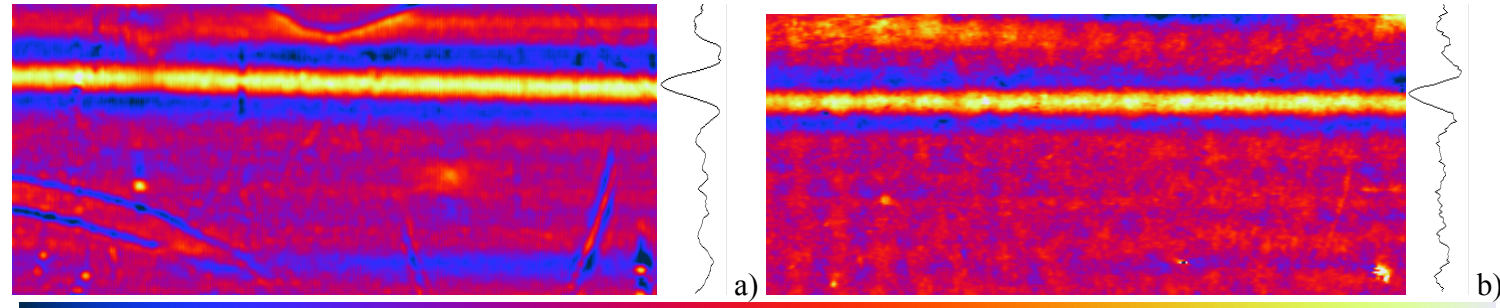

far

$11 \mathrm{~nm}$

near

Fig. 7. Flat Al-mirror, $\mathrm{MgF}_{2}$ coated, fine structure of the shape: a) tactile, b) FRT

\section{EXAMPLES OF APPLICATION}

\subsection{Polished Freeform Lens}

Spherical lenses are tested by standard interferometry available as commercial systems with outstanding performance. However, a problem arises when the surface has a freeform shape like those in varifocal lenses [9], Fig. 8a. The use of adapted reference waves for the interferometric comparison is nearly impossible, especially in an industrial environment. An additional difficulty is the required high dynamic range of the measurement since over a height difference of some millimeter a resolution of less than one micrometer is demanded. The fringe reflection technique (FRT) can be adapted to this problem in an elegant way. The set-up is a standard one with a monitor displaying sinusoidal fringes, a CCD camera mounted close to the monitor, and with a computer for the image processing. As mentioned above, the first results out of the measurement are the surface gradients. The first derivative of the gradient is the curvature which is equal to the optical power, which is changing for a varifocal lens over the surface, Fig. $8 \mathrm{~b}$. The gradient field can be integrated to achieve the surface shape. Interesting is again the fine structure of the shape which can be evaluated by subtracting fitted polynomials, Fig. 8c. In this case the peak-to valley values are in the higher nanometer range. However, the measured fine structure clearly demonstrates some properties of the polishing process: One can see the relief of the polishing tool and by this any deviation from the symmetry. More interesting is the effect of the process to build a "mountain"-like structure in the middle of the lens. Furthermore, the counter-measures to this effect deliver a smaller mountain with a grove around. The achieved resolution of some ten nanometers is sufficient in this case. 

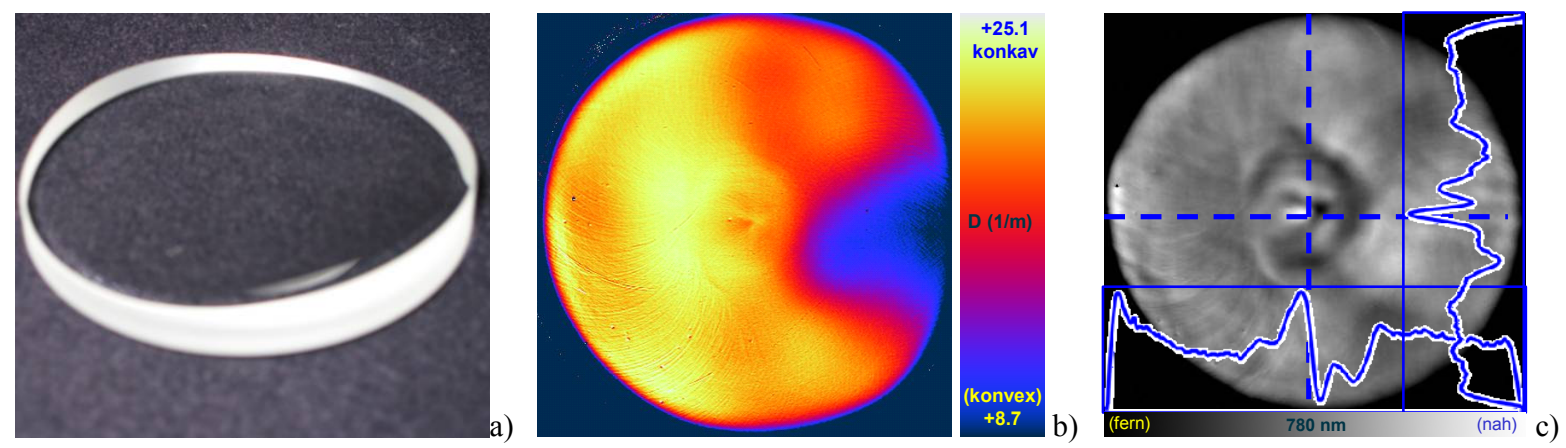

Fig. 8. Freeform lens, plastic: a) photo, b) curvature = optical power, c) scale

\subsection{Flat Silicon Mirror}

High precision metal mirrors with specular surfaces are manufactured today by fly cutting diamond turning [10]. This production method allows to generate flat or spherical surfaces with deviations of a few nanometer compared to the ideal (mathematical) surface. FRT matches the control requirements of such surfaces, too. A flat silicon mirror shall be an example for testing such objects, Fig. 9a. The set-up is comparable to the one described above. It was possible to measure the fine structure directly in this case. The results of the commercial Fizeau interferometer showed a fine structure with peak-to-valley values of $30 \mathrm{~nm}$, Fig. 9b. This is less than the FRT determined, Fig. 9c. The difference can be explained by the limited lateral resolution of the Fizeau interferometer functioning as a low pass filter. This cuts the high peaks and the deep groves of the structure. However, the FRT measurement delivers much more information if the different components are extracted, Fig. 10. One component are the traces of the cutting diamond with peak-to-valley values up to $20 \mathrm{~nm}$, the other significant component is the vibration of the diamond after hitting the substrate with values up to $10 \mathrm{~nm}$. Then there is a random component in the range of $16 \mathrm{~nm}$.
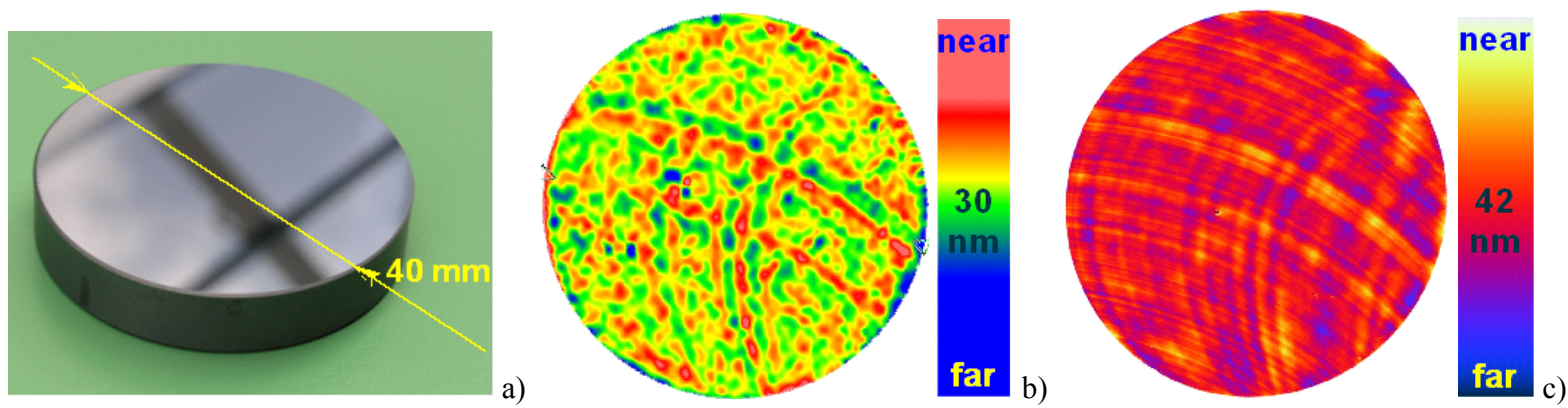

Fig. 9. Flat mirror (Si): a) photo, fine structure measured by b) commercial Fizeau interferometer, c) FRT, both with scale
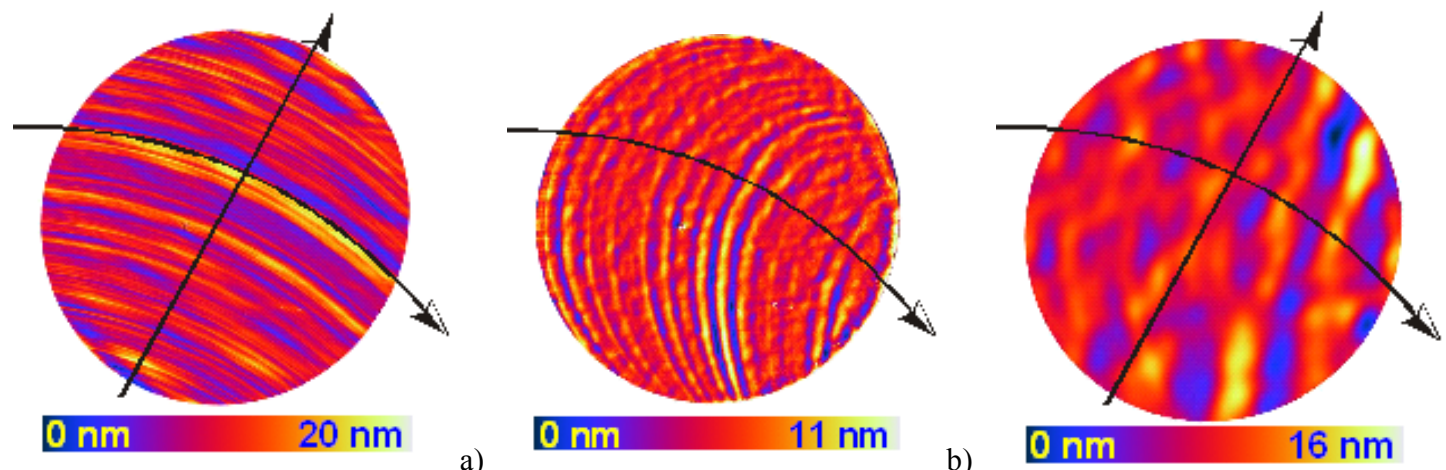

a)

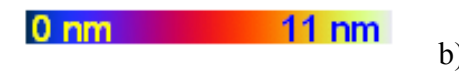

b) $0 \mathrm{~nm} 16 \mathrm{~nm}$

Fig. 10. Flat mirror ( $\mathrm{Si}$ ), fine structure: a) cutting traces b) vibrations of the tool, c) remaining random structure 


\subsection{Internal disturbance of a Lacquer Coating}

The investigation of a lacquer coating on a car door is an example for non specular reflecting surfaces with scattered light components, Fig. 11a. The reflection of the room ceiling light is influenced by different components of the surface structure: overall shape, orange peel effect, local defects, micro structure. FRT was applied to investigate the contribution of the each layer of the coating onto the final structure of the surface. The measurements were performed with a setup comparable to the one that was used for the car window. The results at the final layer - visible for the customer - are an excellent demonstration for the high dynamic range of the FRT in one acquisition of the data: The shape of the shown area of the door has a height range of $1.8 \mathrm{~mm}$, Fig. 11b. The processing of the data by means of subtracting fitted polynomials unfolded an interesting detail: Before the first layer someone has marked a certain point, Fig. 11c. This marking could not be recognized by bare eye since the peak-to-valley height was less than $10 \mu \mathrm{m}$ and thus below the values of the orange peel effect. Taking into account that the resolution is better than $1 / 10$ of the range the dynamic range of the FRT can be calculated to be better than $1 / 10,000$ of the original captured data.
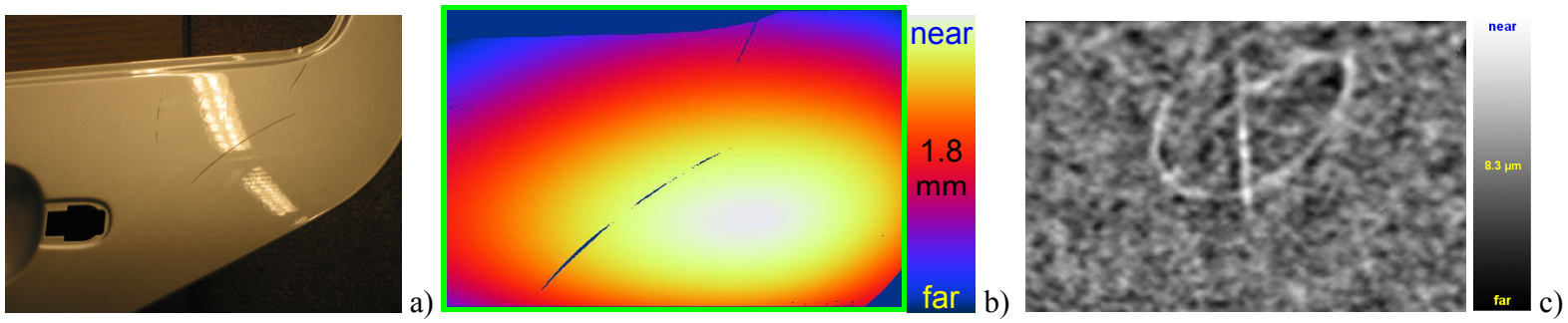

Fig. 11. Lacquer: a) photo, b) shape with scale, c) FRT, both with scale

\section{SUMMARY AND FUTURE WORK}

Shape measurements with a resolution down into the nanometer range are getting an increasing importance. The fringe reflection technique is an appropriate method to fulfill the requirements of scientific and industrial demands on a robust and fast method with a resolution in the nanometer regime and with an extraordinary large dynamic range. The method is based on the imaging of a sinusoidal fringe system via the object surface under investigation. This implies that the surface has to be partly reflective, at least. The common set-up consist of a monitor to display the sinusoidal fringe system, the object, a CCD camera mounted close to the monitor, and an image processing and control software. The evaluation of the imaged fringe system is performed using the phase shifting method. In order to speed-up the measurement the periods of the sequential fringe systems are chosen in a hierarchical way and not as most common in a binary sequence.

The gradient field of the tested surface changes the fringe system. In the simplest case of real flat mirror without any structure the change would be a deflection of the image with a displacement of the fringe system on the target. More complex surfaces deform the fringe system according to the gradient field of the shape. The evaluation of the displacement field is derived on the base of geometrical relations and optical laws. The resulting equation yielded that the resolution depends on three quantities: the pixel size of the camera, the f-number of the object and resolution of the measured fringe phase. The choice of reasonable parameters results in an achievable height resolution of less than $1 \mathrm{~nm}$. This has been proven with a flat coated mirror.

Three examples demonstrated the versatility of the fringe reflection technique:

- The first example was the measurement of the shape of a freeform lens for varifocal glasses. This object is hard to be tested by standard interferometric methods since it is highly difficult to generate the reference wave. In this case a grating interferometer served as reference. The peak-to-valley values of the height were nearly $10 \mathrm{~mm}$. The fine structure of the shape could be extracted out of the original shape data. This fine structure with peak-to-valley values in the nanometer regime showed properties of the polishing especially a peak in the middle with a surrounding grove.

- The second example was the measurement of the shape of a flat silicon mirror. It was produced by fly cutting diamond turning being the most precise technique for specular surfaces. The evaluation of the fine structure of the shape showed three different components: the traces of the cutting diamond, vibrations of the tool introduced by the interaction with the work piece after the first contact, and a random part due to several reasons. The range of the peakto-valley values were below $20 \mathrm{~nm}$ with a resolution better than $1 \mathrm{~nm}$. 
- The third example was the investigation of the lacquer coating of a car door. The fringe reflection method enabled the determination of each layer of the coating onto the final orange peel effect of the surface. On the overall shape with a height of about $2 \mathrm{~mm}$ a fine structure could be extracted with height values in the upper and a resolution in the lower nanometer range. The evaluation of this component unfolded a mark drawn on the uncoated surface by a coworker. Although the maximum height of this mark was in the range of micrometer it could not be seen by the naked eye since the orange peel effect hired it.

The fringe reflection technique has some remarkable properties demonstrated by the examples: The resolution can be below one nanometer, the dynamic range of a measurement is higher than 1:10,000, and the resolution does not depend on the size of the object. Beside this it has to be pointed out that the technique applies white light and needs no protection against environmental disturbances.

Future work will be carried out on large spherical mirrors used e.g. in telescopes or for sun farms in solar energy plants. Another challenging task will be the application to dynamic objects, e.g. the behaviour of liquid surfaces or the interaction of biological species with a liquid environment.

\section{ACKNOWLEDGEMENTS}

The authors whish to thank their colleagues who have contributed in very different ways. Especially named shall be Wolfgang Osten, BIAS, ITO, for his encouragement of the work especially in the beginning, and Wansong Li, VEW, for his huge input into the work of the applications.

Special thanks shall be given to the DFG - German Research Association and the BIG/InnoWi, Bremen, for their financial support over many years.

Last but not least, the remarkable sponsorship of the industry, mainly the companies VEW - Vereinigte Elektronikwerkstätten, satisloh, and Airbus GmbH has enabled this work in an extraordinary manner. Thank you.

\section{REFERENCES}

[1] Savio, E.; De Chiffre, L. \& Schmitt, R., "Metrology of freeform shaped parts", CIRP Annals - Manufacturing Technology, 56(2), 810-835 (2007).

[2] Osten, W. Kayser, D., Bothe, T. and Jüptner, W., "High Resolution Measurement of Extended Technical Surfaces with Scalable Topometry", SPIE Vol. 4101, 168-174 (2006)

[3] Bothe, T., Li, W., Kopylow, C., and Jüptner, W.: "High Resolution 3D Shape Measurement on specular surfaces by fringe reflection", Proc. SPIE Vol. 5457, 411-422, , (2004)

[4] Li, W., Bothe, T., Kopylow, C., Jüptner, W.: "Evaluation Methods for Gradient Measurement Techniques", Proc. SPIE Int. Soc. Opt. Eng. 5457, 300-311, (2004)

[5] Burke, J.; Bothe, T.; Osten, W.; Hess, C.: "Reverse engineering by fringe projection“. Proc. SPIE Vol.4778, 312324,2002

[6] www.fringeprocessor.com

[7] Creath, K.: "Phase shifting holographic interferometry", in Holographic Interferometry, Springer Series in Optical Sciences 68, 109-150 (1994)

[8] Osten, W. Seebacher, S. Baumbach, T. Jüptner, W. "Absolute shape control of microcomponents using Digital holography and multiwavelength contouring", Proc. SPIE 4275, 71-84, (2001)

[9] Bothe, T.; Li, W.; v. Kopylow, C. and Bergmann, R., "The Fringe Reflection Technique for Lens Inspection and Specular Freeform Measurement", MAFO Ophthalmic Labs \& Industry 5(1), 38-42, (2009).

[10] Gläbe, R., Flucke, C., Bothe, T. Brinksmeier, E.: High Speed Fringe Reflection Technique for nm Resolution Topometry of Diamond Turned Free Form Mirrors, Proc. Euspen 5th Int. Con., Vol. 1 (2005), 25-28 